\title{
MORPHOLOGIC SPECTRUM OF EBSTEIN'S MALFORMATION: REVISITATION RELATIVE TO SURGICAL REPAIR
}

Christian Schreiber, MD

Andrew Cook, BSc

Siew Yen Ho, PhD, FRCPath

Norbert Augustin, MD

Robert H. Anderson, MD, FRCPath
Objective: Our aim was to elucidate the morphologic spectrum of Ebstein's malformation of the tricuspid valve with regard to diagnosis and the feasibility of surgical repair, in the light of the currently favored reconstructive techniques. Methods: We examined 23 autopsied hearts. Taking the displacement of the septal and mural leaflets of the abnormal tricuspid valve as our diagnostic criterion, we focused subsequently on the location of the distorted valvular orifice and the attachment and formation of the anterosuperior leaflet. We also assessed the dimensions of the components of the right ventricle relative to the plane of the displaced valvular orifice. Results: In all hearts, the septal and mural leaflets were hinged at various points within the inlet of the right ventricle. In many cases, however, these leaflets were virtually absent. The plane of the effective tricuspid valvular orifice was displaced anterosuperiorly to varying degrees. In the most severe forms, the valvular mechanism took the form of a 1-leaflet valve. The length of the functional right ventricle when compared with the left ventricle ranged proportionally from 0.6 to 1.1 (mean, 0.9). Conclusions: Ebstein's malformation is much more than simple "downward displacement" of the leaflets. In essence, the valvular orifice is formed within the ventricular cavity at the junction of the atrialized inlet and functional ventricular components. When surgical intervention becomes necessary, it is essential to make a detailed assessment of both valvular and ventricular abnormalities. (J Thorac Cardiovasc Surg 1999;117:148-55)
E bstein's malformation exhibits a spectrum of pathologic features. ${ }^{1,2}$ Management depends on the anatomic severity of the lesion, but correlation between anatomic and clinical severity is difficult to establish. Furthermore, the method of surgical treatment of patients whose condition requires intervention remains

From the Section of Pediatrics (S.Y.H., R.H.A.), Imperial College of Medicine at the National Heart and Lung Institute, London, United Kingdom; Departments of Pathology and Perinatal Cardiology (A.C.), Guy's Hospital, London, United Kingdom; German Heart Center (C.S., N.A.) at the Technical University of Munich, Germany.

During this investigation C.S. was a visiting fellow from the German Heart Center Munich at the Technical University of Munich, Germany. S.Y.H. and R.H.A. are supported by the British Heart Foundation and the Joseph Levy Foundation.

Received for publication May 19, 1998; revisions requested July 9, 1998; revisions received July 30, 1998; accepted for publication Aug 6, 1998 .

Address for reprints: S. Y. Ho, PhD, FRCPath, Paediatrics, Imperial College School of Medicine, National Heart and Lung Institute, Dovehouse St, London SW3 6LY, United Kingdom.

Copyright (๑) 1999 by Mosby, Inc.

$0022-5223 / 99 \$ 8.00+0 \quad \mathbf{1 2 / 1 / 9 3 6 5 6}$ a matter of controversy. During the evolution of corrective surgery, options have centered either on replacement of the abnormal valve with a prosthesis, on plication and annuloplasty of the abnormal tricuspid valvular apparatus, or on a combination of valvular replacement and plastic repair. ${ }^{3-7}$ More recently Carpentier and colleagues $^{8}$ and Chauvaud and colleagues, ${ }^{9}$ and subsequently the surgical team at the German Heart Center in Munich, ${ }^{10}$ have emphasized the advantages of valvular reconstruction. They have achieved conservative repair in large series of patients, with results equally as good as those obtained with the classic "Hardy" approach, as promoted by Danielson and colleagues. ${ }^{11}$ The classic technique involves plication of the atrialized right ventricle parallel to the atrioventricular groove. The Parisian surgeons plicated the atrialized ventricular component parallel to the ventricular septum. In addition, they recommended mobilization of the abnormal anterosuperior leaflet of the malformed tricuspid valve. The Munich group, in contrast, favored a 1-leaflet repair and did not resort to annular plication. With these various anatomic and surgical considerations in mind, 

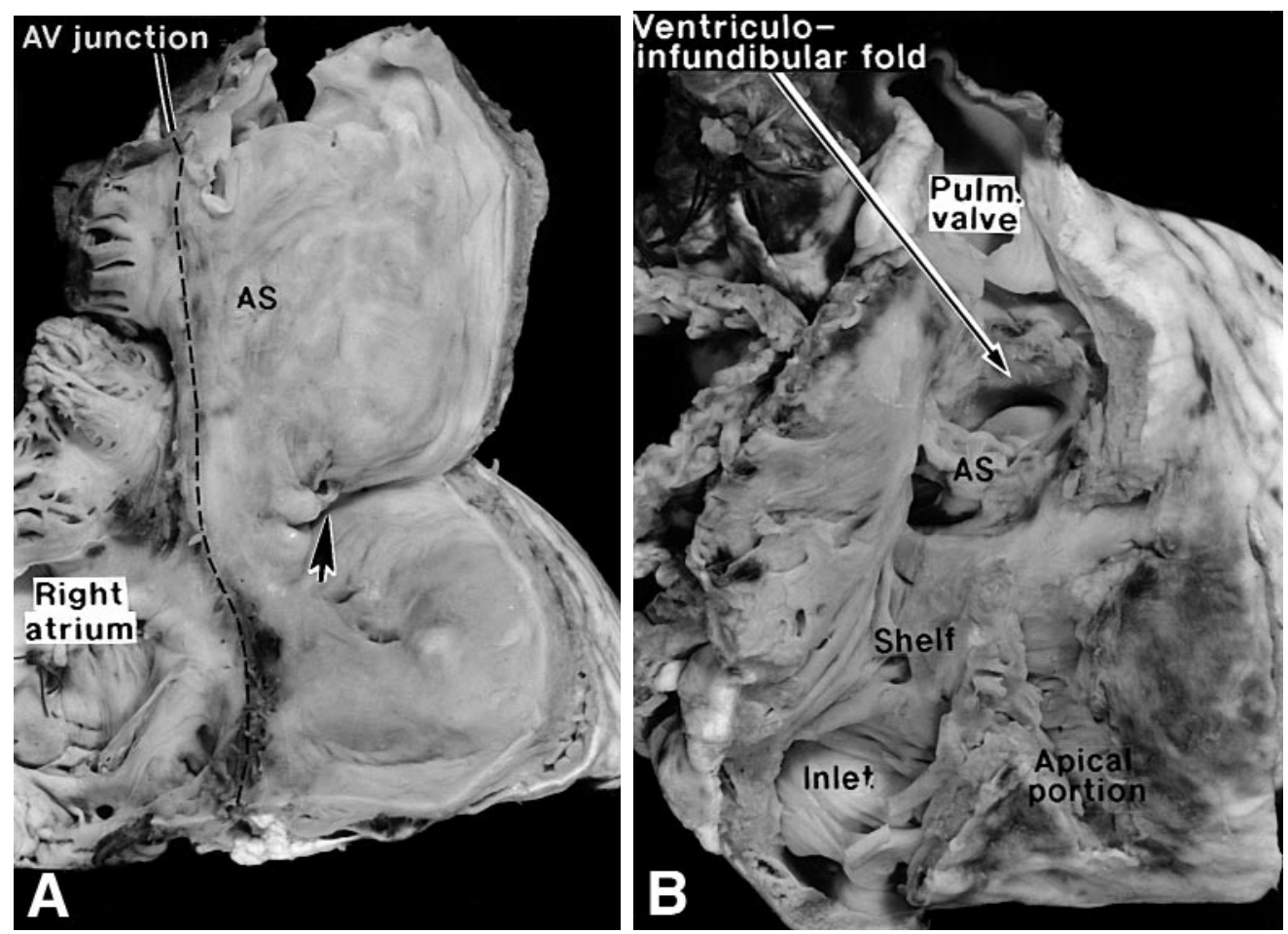

Fig 1. A, The septal and mural leaflets in this heart have not developed. Only the anterosuperior leaflet $(A S)$ has delaminated, but its distal edge is attached to a muscle shelf at the junction between the inlet and apical trabecular portions of the right ventricle. The valvular orifice is at the site of the anteroseptal commissure (arrow). AV, Atrioventricular. B, This view of the right ventricular outlet shows the location of the muscle shelf. The orifice of the tricuspid valve is restricted to the area between the free margin of the anterosuperior leaflet and the ventriculoinfundibular fold.

we have now revisited the pathologic features with a view to elucidating diagnostic aspects and establishing those morphologic features of surgical impact. In this way, as far as it is possible by examination of autopsied specimens, we aimed to establish the feasibility of each of the reconstructive surgical techniques. In addition to the well-recognized "downward displacement" of the septal and mural leaflets, which is the criterion for diagnosis, we focused also on the attachment and formation of the anterosuperior leaflet and particularly on the location of the distorted valvular orifice and the site of apposition of its involved leaflets. We assessed this anatomic detail in the light of the dimensions of the components of the right ventricle relative to the plane of the displaced valvular orifice.

\section{Materials and methods}

There are 39 formalin-preserved hearts with Ebstein's malformation in the cardiopathologic collection of the Royal Brompton Campus of Imperial College School of Medicine and the pediatric cardiopathologic museum of Guy's Hos- pital. For the purpose of this study, we excluded 2 hearts with an imperforate tricuspid valve, 6 hearts with coexisting pulmonary atresia, 7 hearts with congenitally corrected transposition, and 1 heart with previous replacement of the abnormal tricuspid valve. The age at the time of death in the remaining 23 patients had ranged from 20 weeks of gestation to 39 years. Special attention was paid to the location of the displaced tricuspid valvular mechanism, the morphologic features and dimensions of its leaflets, and the dimensions and structures of the right heart. We measured the dimensions of the right atrium from the lateral wall to the atrial septum and from the atrioventricular junction to the atrial roof. The atrialized component of the right ventricle was quantified by charting the distance from the atrioventricular junction to the most distal displacement of the effective valvular orifice. The range of distal attachment of the anterosuperior leaflet was judged according to the distance from its leading edge to the ventricular apex. The functional right ventricle was then measured from the apex to the basal hinge of the pulmonary valvular leaflets. We assessed also the mural thicknesses of the various ventricular components. We determined the diameter of the tricuspid valve at the level of its displaced orifice. The level of the displaced orifice was determined by bringing 


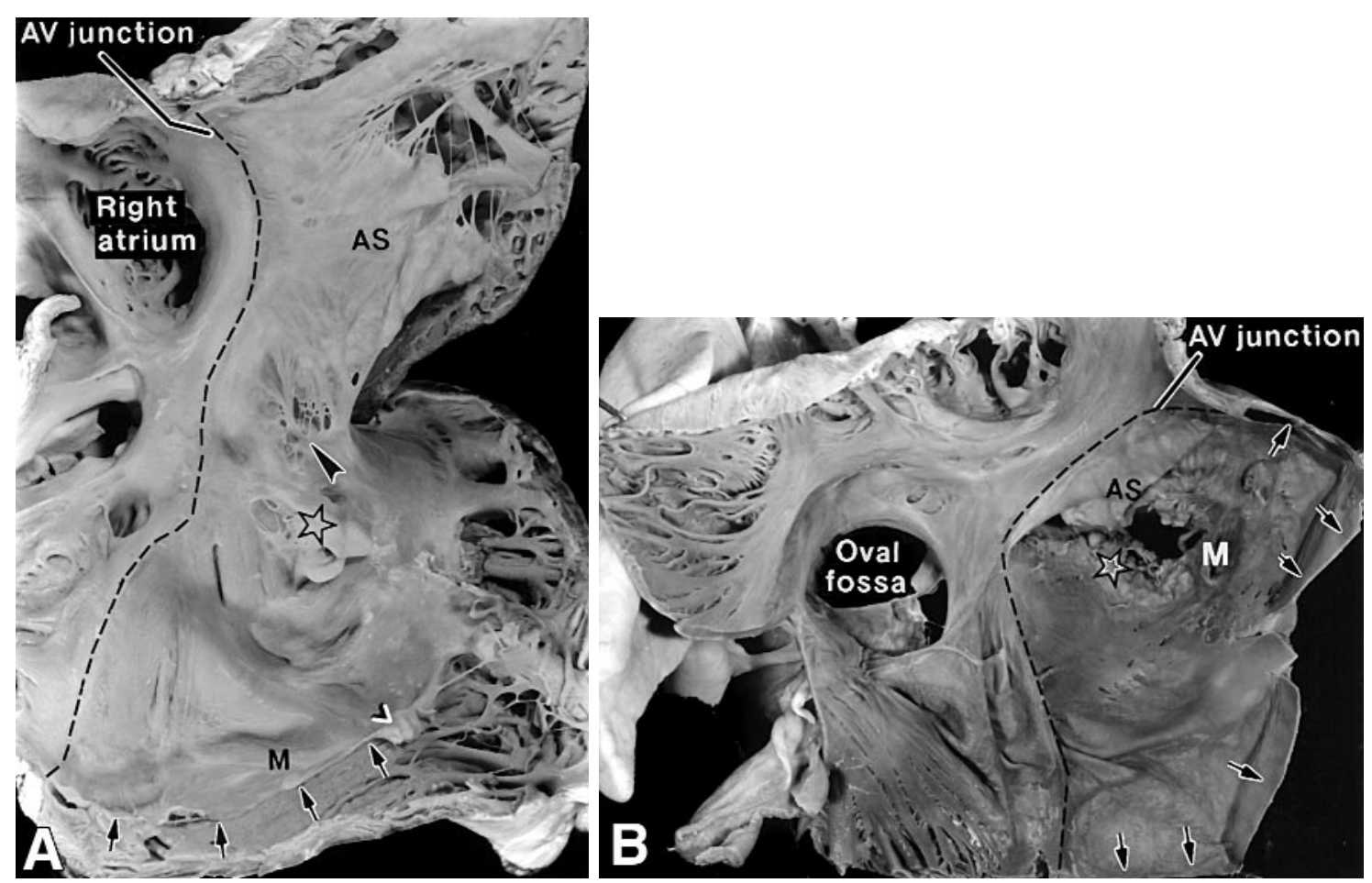

Fig 2. A, The septal leaflet in this heart is represented by a cauliflower-like excrescence (star). The anterosuperior leaflet $(A S)$ is sail-like and hinged at the atrioventricular $(A V)$ junction. Tendinous chords at the anteroseptal commissure (arrowhead) attach directly to the ventricular septum. The mural leaflet $(M)$ is adherent to the ventricular wall (arrows) and has a minimal flee edge $(V)$. B, The septal (star) and mural $(M)$ leaflets are formed, but the hinge line is displaced well into the right ventriicular cavity. Note the thin, atrialized ventricular wall (arrows along cut edge).

the leaflets as close to coaption as could be achieved by manipulation with forceps. The angle between the orifice and the plane of the right atrioventricular junction was estimated by displaying the specimens in a simulated right anterior oblique projection. To provide a control for these findings, we also measured the diameters and dimensions of the left-sided valves and chambers, using in this way each heart as its own control. Special interest was directed to the coronary arterial anatomy at the posterior surface of the heart. Associated cardiac malformations, other than those representing part of Ebstein's malformation, were included in our descriptions.

\section{Results}

Valvular structure and position. In all 23 hearts we found, by definition, a certain "downward displacement" of the hinges of the leaflets of the tricuspid valve, but this displacement was confined to the septal and/or mural (inferior) leaflets. As a consequence of the displacements, the valvular mechanism in most hearts was formed at the junction between the atrialized inlet and the remaining apical and trabecular components of the right ventricle. The displacement was minimal in only 1 of our autopsied hearts. In contrast, displacement was considered complete in another heart where there was a total lack of formation of both septal and mural leaflets, and in which the anterosuperior leaflet was small (Fig 1). In another 2 cases, the septum was devoid of any leaflet tissue. In 15 other cases, the septal leaflets showed relatively small mobile parts, with the remaining tissue being nodular and, as viewed in the specimens, functionless (Fig 2, A). Although well formed in the remaining hearts, the septal leaflets were thickened and nodular in appearance (Fig 2, B).

The mural leaflet was absent in 3 hearts, including the case with absence of the septal leaflet. In 8 hearts, the mural leaflet was barely developed and appeared only as a small fibromuscular flap in 4 of these (Fig 3, $A)$. In the remaining specimens, where the mural leaflet was formed, it was usually small. It was fused to varying extent with the anterosuperior leaflet in 11 hearts, resulting in presence of one or more accessory orifices. Complete fusion in 4 hearts made it impossible to distinguish one leaflet from another. In other cases, where 

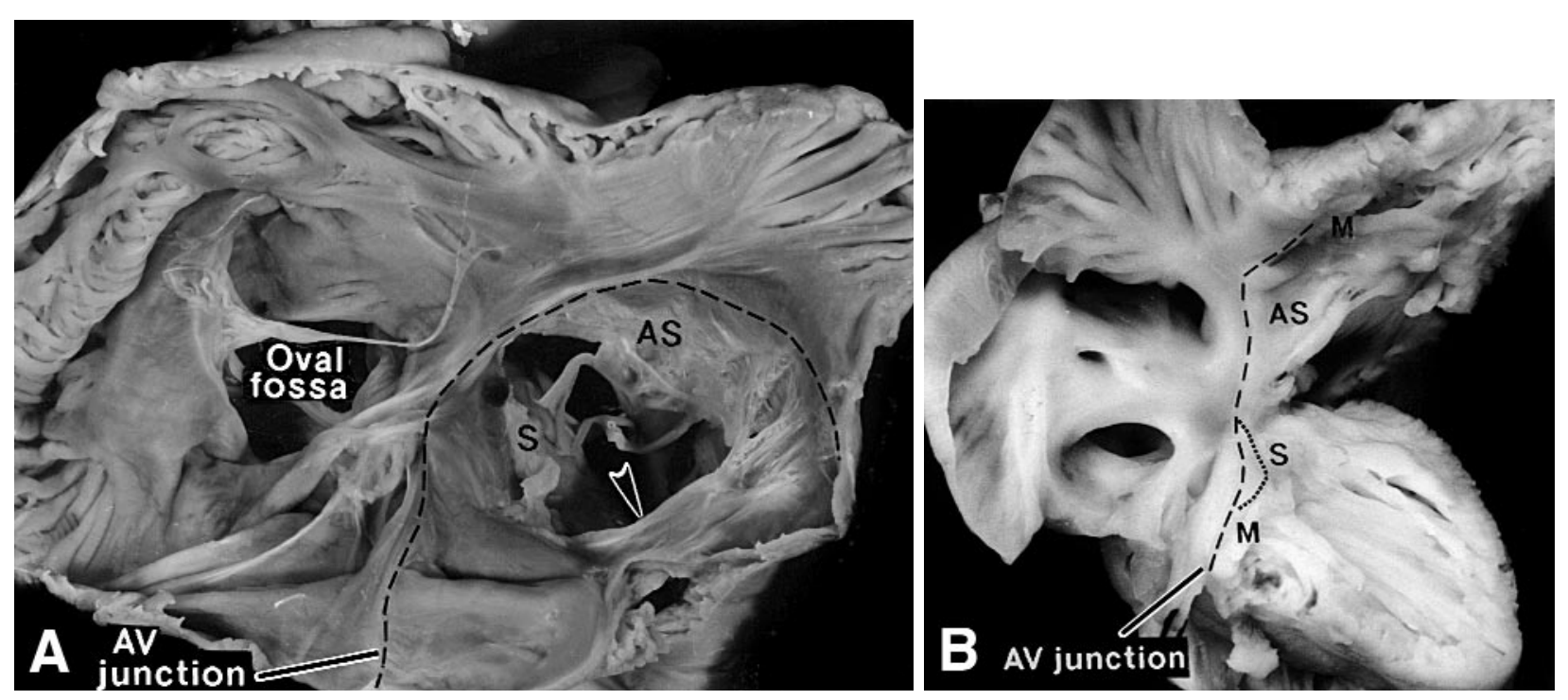

Fig 3. A, The mural leaflet (arrowhead) is represented by a fibromuscular flap. The anterosuperior leaflet $(A S)$ has focal attachments, but the valvular orifice is divided by 2 strands of accessory valvular bridges. B, This dissection through the mural leaflet $(M)$ shows its hinge at the atrioventricular $(A V)$ junction. The hinge (dotted line) of the septal leaflet $(S)$ is displaced apically.

there was a free edge to the mural leaflet, the maximal displacement of its hinge into the right ventricle was $20 \%$ to $97 \%$ of the length of the inlet distal to the atrioventricular junction. The mural leaflet was hinged at the atrioventricular junction in 3 specimens, along its entire span in 1 specimen (Fig 3, B), and parietally in the other 2 specimens.

In all but 3 hearts, the anterosuperior leaflet was enlarged and sail-like. Instead of being entirely a fibrous sheet, as in the normal heart, it showed varying degrees of muscularization and marked variations in its distal attachment. In 3 hearts, the distal attachment was almost like a normal valve, with tethering at the medial and the anterior papillary muscles (Fig 4, A). In 15 hearts, the leading edge of the leaflet was attached in linear fashion directly to an anomalous muscle shelf at the junction between the inlet and apical trabecular portions of the right ventricle (Fig 4, B). In 5 hearts the distal edge was attached via tendinous chords to the shelf, to multiple papillary muscles, or to the ventricular wall, leaving gaps at the intercordal spaces (Fig 4, C). Complete fusion between the anterosuperior and mural leaflets in 4 hearts left a keyhole orifice between the inlet and outlet ventricular components at the usual site of the anteroseptal commissure (Fig 5). The valvular mechanism seemed competent in these 4 hearts, although the tricuspid valvular orifice was smaller than the mitral, with ratios from 0.7 to 0.9 . In the remaining hearts, the tricuspid valvular orifice was larger than the mitral, with ratios 1.3 to 1.8 . We estimated that the latter examples would have been severely regurgitant in the beating heart.

The effective valvular orifice was pivoted on the anteroseptal commissure but rotated by between 10 and 90 degrees from the level of the atrioventricular junction in nearly all specimens (Fig 6). Because of the lack of development of all the peripheral commissures, the orifice was parallel to the atrioventricular junction in 1 specimen. The medial papillary muscle could not be distinguished in 9 hearts. When present, it was tiny in 4 hearts.

Ventricular dimensions and structure. The dilated right atrium and the atrialized component of the right ventricle were of almost equal size, with a mean ratio of 1.1. Excluding the case where valvular displacement was complete, the ratio of the atrialized right ventricle, as measured from the atrioventricular junction to the most distal displacement of the effective valvular orifice relative to the remaining trabecular part of the ventricle to the apex, ranged from 1.4 to 3.1 (mean, 2.1). Within the functional right ventricle, it was possible to recognize the apical trabecular part, the infundibulum, and a portion situated between the ventricular wall and the abnormally tethered anterosuperior leaflet. Compared with the left ventricle, the ratio between the length of the functional right ventricle and the left ven- 

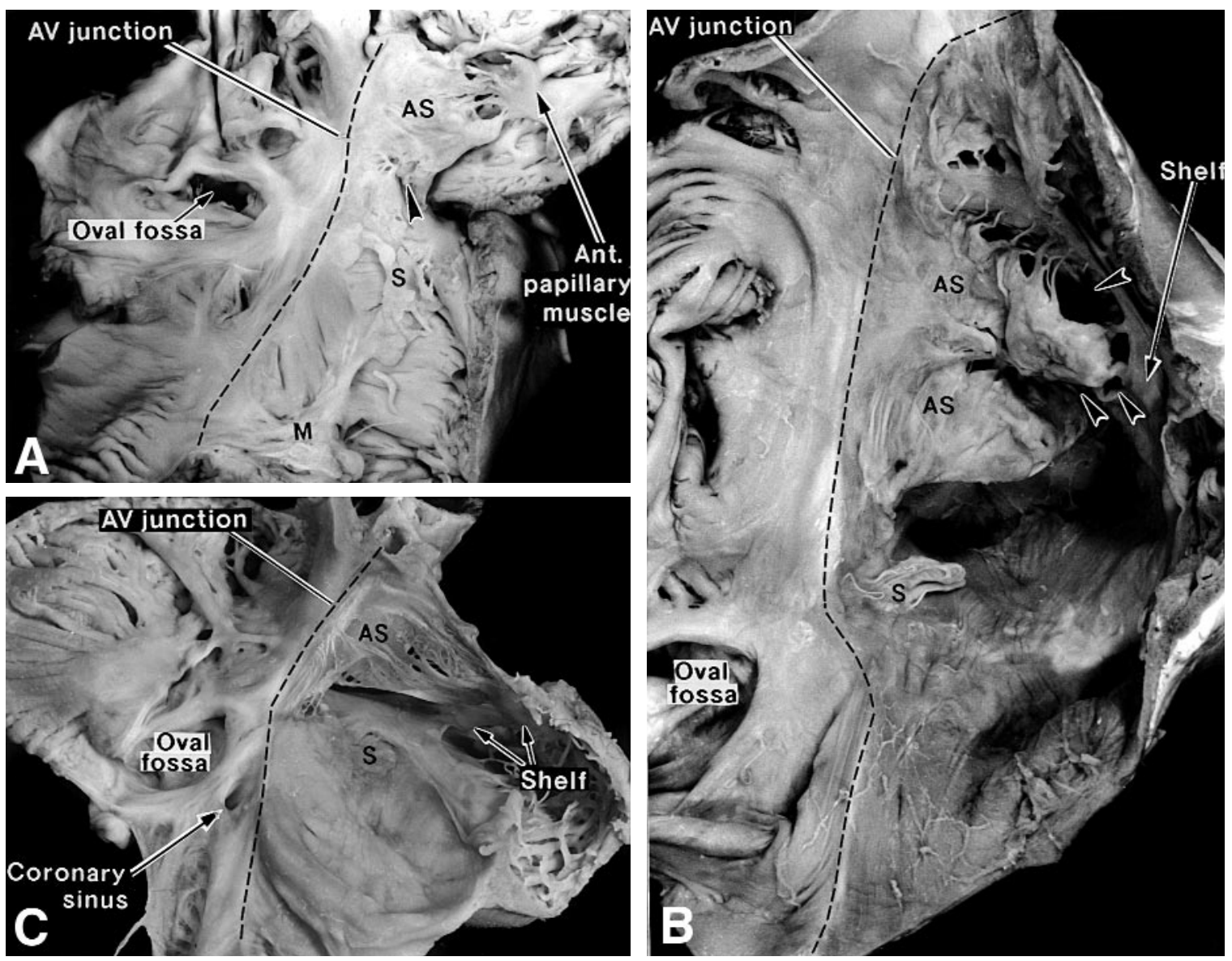

Fig 4. A, The anteroseptal commissure (arrowhead) is not well developed in this heart, but the anterosuperior leaflet is shallow and has focal attachments to the anterior-papillary muscle. B, The anterosuperior leaflet $(A S)$ in this heart is scalloped, with hyphenated attachments distally to a muscle shelf. Multiple interchordal spaces (arrowheads) are present. $\mathbf{C}$, In this heart, the distal edge of the anterosuperior leaflet $(A S)$ is attached linearly to the muscle shelf although a few small perforations are present in the body of the leaflet. The septal leaflet $(S)$ is barely formed.

tricle ranged from 0.6 to 1.1 (mean, 0.9). In only 3 cases was the outlet of the right ventricle considered restrictive. The wall of the atrialized right ventricle was thinned and fibrotic, containing only sparse muscular fibers. It had a mean thickness of $3.3 \mathrm{~mm}$, compared with a mean of $4.8 \mathrm{~mm}$ for the wall of the functional right ventricle, the latter also being thinned and fibrotic. The mean mural thickness of the left ventricle was $6.9 \mathrm{~mm}$.

Coronary arteries and associated lesions. The right coronary artery was dominant in only $52 \%$ of the hearts. In these, it ran within the right atrioventricular groove, gave rise to the posterior interventricular artery, and then continued to supply the diaphragmatic surface of the left ventricle. In $39 \%$ of the hearts, the posterior descending artery was a branch of the circumflex art- ery, which continued beyond the crux to give twigs to the diaphragmatic wall of the atrialized right ventricle. In the remaining $9 \%$, we found a balanced pattern, with both the right coronary artery and the circumflex artery giving rise to parallel descending branches. The dilated atrialized right ventricle displaced the right coronary artery and its branches posteriorly.

All but 2 of the 23 specimens had a shunt at the atrial level; this was an atrial septal defect in 8 specimens and a patent oval foramen in 13 specimens. Two hearts showed a deformity of the mitral valve. One heart showed a 2-chambered right ventricle with a small ventricular septal defect, and previous banding of the pulmonary trunk had been performed in this specimen. Surgery had been performed in another heart to relieve stenosis of the pulmonary valve. 


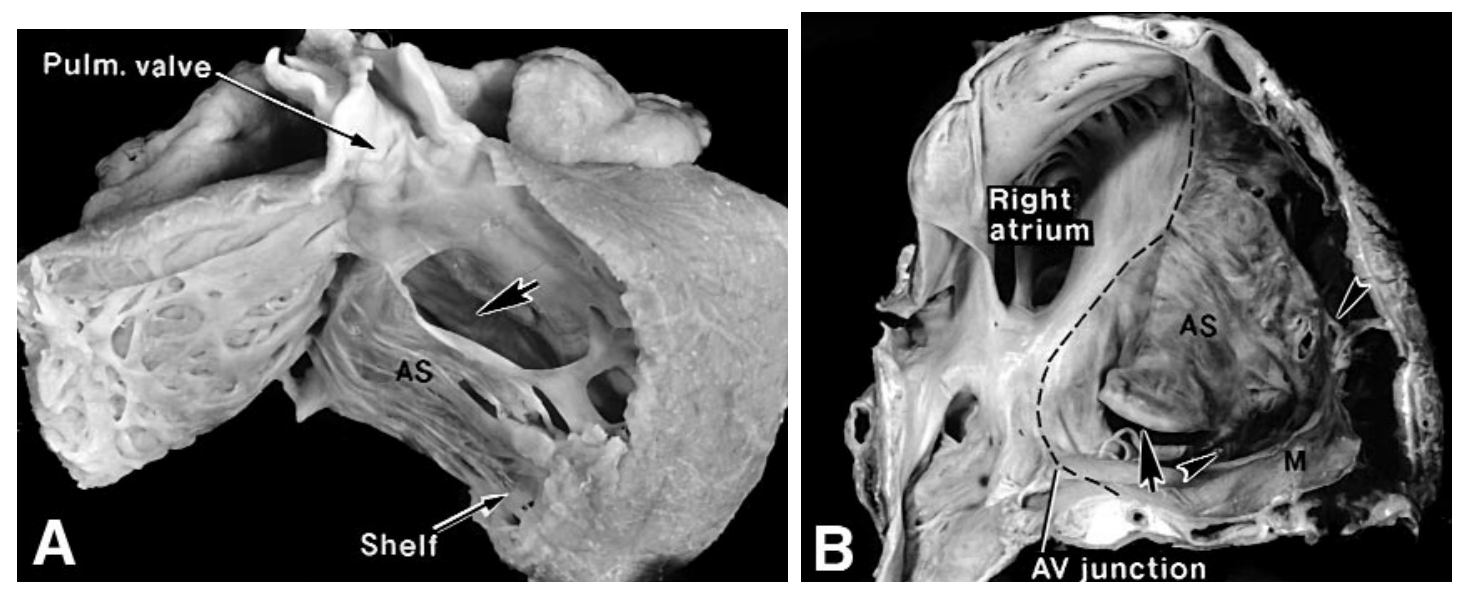

Fig 5. A, This view of the right ventricular outflow tract shows the keyhole (arrow) at the site of the anteroseptal commissure. There is linear attachment of the anterosuperior leaflet $(A S)$ to the muscle shelf. $\mathbf{B}$, This heart shows the keyhole (arrow) from the inlet aspect. There is no separation of the distal edges of the mural $(M)$ and anterosuperior $(A S)$ leaflets (between arrowheads). Consequently, the valvular orifice is restricted to the site of the anteroseptal commissure.

\section{Discussion}

We recognize that it is somewhat presumptuous to try to predict which of the many proposed variations for repair of Ebstein's malformation will prove most efficacious. We also appreciate that the number of hearts we have studied is smaller than most surgical series. It remains an undeniable fact, nonetheless, that the exposure afforded the morphologist is much greater than that obtained by the surgeon. In this light, our continuing studies offer insights that, at least to us, are novel and pertinent to surgical repair. Thus the morphologic spectrum of Ebstein's malformation is best appreciated when it is recognized that the entity involves far more than simple "downward displacement" of the leaflets of the tricuspid valve. Indeed, the entire valvular mechanism is distorted and, in cases with the most extreme displacement of the leaflets, an effective unifoliate valvular structure is formed toward the apex of the right ventricle, with the line of closure at the junction of the atrialized inlet and the distal functional ventricular cavity. Although this fact may be obvious, it had not been fully appreciated by us after our previous studies. Furthermore, in the specimens in our collection in which this arrangement was most obvious, the valvular mechanism appeared to have been competent. Description in terms of the normally structured tricuspid valve was very difficult in these specimens. In the normal heart, it is possible to distinguish 3 leaflets of the tricuspid valve, because of their location and because zones of apposition can be identified between them when the valve is closed. The normal right ventricle can also be divided morphologically into 3 components. ${ }^{12}$

In the presence of Ebstein's malformation, the location of the hinges of the septal and mural leaflets, or their remnants, means that all or part of the ventricular inlet portion becomes physiologically part of the right atrium, thus representing the so-called atrialized component of the right ventricle. ${ }^{2}$ In keeping with this atrialization, the entire plane of the tricuspid valvular orifice and the line of closure of its leaflets is tilted toward the junction of the inlet with the remaining functional portions of the right ventricle. In most of the hearts, this junction was clearly marked by the abnormal distal attachments of the anterosuperior leaflet and was seen as a discrete shelf. Despite this effective loss of its inlet component, now incorporated hemodynamically as part of the enlarged right atrium, the functional right ventricle remained of moderate or good size when its length was compared with that of the left ventricle.

Most significantly, the anterosuperior leaflet was always present and was normally attached proximally at the atrioventricular junction. It was the size and distal attachments of this leaflet that determined the function of the displaced valvular orifice and the severity of the disease. In nearly one half of the specimens, the mural leaflet was incorporated as part of the abnormal anterosuperior leaflet. In these cases, when the nodular septal leaflet was also recognizable as such, what would in normal hearts be a 3-leaflet valve seemed at first to be arranged as a 2-leaflet valve. On further study, however, we determined that the valvular mech- 


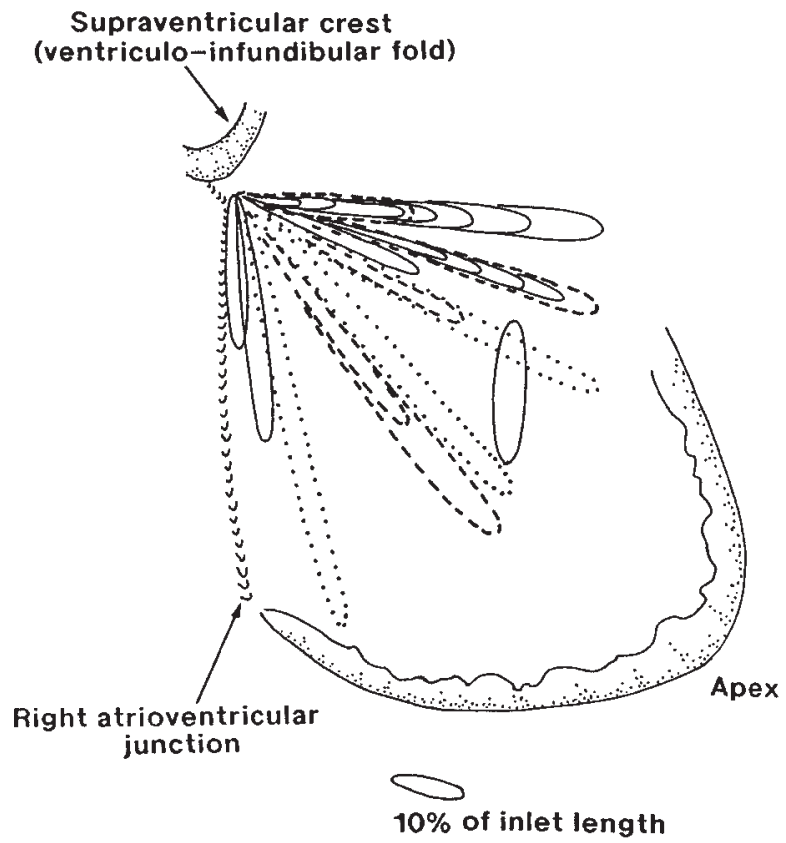

Fig 6. This is a stylized representation of the angle of tilt of the effective valvular orifice (ellipses) as estimated from the 23 specimens. The solid lines represent the cases with linear attachment; the ellipses with dotted lines and broken lines represent hearts with focal and hyphenated attachment of the anterosuperior leaflet, respectively. The vertical elipse represents the solitary case with the orifice parallel to the atrioventricular junction. The scale represents the maximal width of the orifice as a percentage of the distance between the atrioventricular junction and the apex of the right ventricle measured along the acute margin.

anism would function as a 1-leaflet valve, because the extremely nodular septal leaflet was never sufficiently mobile to play a part in valvular closure. In 4 hearts, as already discussed and as far as we could establish within the constraints of a retrospective autopsy examination, the displaced valvular mechanism was judged to be competent. In these hearts, the huge sail-like anterosuperior leaflet either had no perforations and no significantly reduced mobility or was tethered to produce a "keyhole" at the anticipated site of the anteroseptal commissure. Surgery in these hearts, with the most severe anatomic distortions, would have been needed only if dilation of the right heart had impeded coaptation of the leaflets during life. The remaining hearts, in contrast, were judged to have had marked insufficiency during life, either because of dilation of the valvular orifice or the presence of multiple perforations and communications between the tendinous chords attaching the apical parts of the anterosuperior leaflet to the ventricular wall or to the anomalous muscular shelf. As already emphasized in previous studies, ${ }^{13,14}$ these abnormal connections and tetherings, linear or hyphenated attachments, would have prohibited normal motion of the leaflet.

The size of the dilated right atrium and atrialized portion of the right ventricle made the functional right ventricle, in proportion, look extremely small. As indicated, this was spurious, because when comparison was made with the left ventricle, the average ratio of ventricular lengths, albeit a crude indicator of ventricular size, was 0.9 . This would suggest that, from the morphologic point of view, restoration of the right ventricle is indicated only in the cases where the anterosuperior leaflet is abnormally attached to the inlet-trabecular junction or is adherent to the ventricular wall or where the abnormal attachments produce obstruction of the subpulmonary outflow tract. The concept for repair promoted by Carpentier and colleagues ${ }^{8}$ takes into account such findings and emphasizes the need to mobilize the anterosuperior leaflet and reattach it at the atrioventricular junction. This requires concomitant reduction of the circumference of the atrioventricular anulus, achieved by performing longitudinal plication of the atrialized inlet and the adjacent right atrium. Neither the Hardy repair nor the Munich technique would permit reconstruction in these severe cases. The results of surgical repair from the Mayo Clinic and from Munich, ${ }^{10}$ nonetheless, show that enlargement of the functional right ventricle is not necessarily required in those variants of the anomaly that do not have gross tethering of the anterosuperior leaflet. The success of all the techniques depends on the size and structure of the anterosuperior leaflet. A thickened, muscularized, and small leaflet, as found in some of the hearts, does not provide the mobility for a functional valve. This arrangement would likely necessitate valvular replacement, although the Parisian approach may permit salvage in such hearts. Whether it is always necessary to reduce the size of the atrialized right ventricle by plication has yet to be demonstrated objectively.

The technique used in Munich, producing as it does a unifoliate repair, resulted in significant clinical improvements and a marked decrease in heart size, best explained by the dramatic reduction of valvular insufficiency achieved after the surgical reconstruction. This, therefore, seems to be one major key to surgical repair. In fact, plication prolongs the time needed for cardiopulmonary bypass and, when performed parallel to the ventricular septum, courts the risk of injury or kinking of the branches of the right coronary artery. Branches of this artery would have been at risk in at 
least two thirds of our specimens. It was of note that dominance of the circumflex artery, or a balanced arrangement, was found in $48 \%$ of our specimens. This is in marked contrast to the proportion of $10 \%$ found in normal hearts.

When surgical intervention becomes necessary, a detailed assessment of all the salient morphologic evidence is essential. Cross-sectional echocardiography is now recognized as the preferential diagnostic tool, ${ }^{13,15,16}$ because angiography does not permit the required detailed morphologic assessment. ${ }^{14}$

Based on our anatomic observations, it would seem that echocardiography can define accurately all the features essential to surgical repair. The location and size of the valvular plane and orifice can be assessed once their abnormal location is appreciated. The abnormal distal attachments of the anterosuperior leaflet and the implications of these attachments on division of the right ventricle can be defined. A description of the size and attachments of the septal and mural leaflets can be provided in relation to the abnormal formation of the anterosuperior leaflet. The displacement of the septal leaflet is best displayed in apical 4-chamber views, although the mural leaflet, when present, is seen in subcostal and parasternal long-axis views. The anterosuperior leaflet and its distal attachment can be demonstrated in apical 4-chamber views and parasternal long- and short-axis views. Doppler echocardiography is valuable in evaluating any degree of obstruction, and color Doppler will demonstrate tricuspid regurgitation. As for determining the surgical treatment of choice, it goes without saying that the abnormal anatomy must be fully understood. It is then prior experiences and results that will help to decide which approach is adequate and feasible for each individual patient. The marked heterogeneity observed in our series suggests that an eclectic approach may prove more efficacious than attempts always to use the same procedure.

\section{REFERENCES}

1. Becker AE, Becker MJ, Edwards JE. Pathologic spectrum of dysplasia of the tricuspid valve. Arch Pathol 1971;91:167-78.
2. Zuberbuhler JR, Allwork SR, Anderson RH. The spectrum of Ebstein's anomaly of the tricuspid valve. J Thorac Cardiovasc Surg 1979;77:202-11.

3. Hunter SW, Lillehei CW. Ebstein's malformation of the tricuspid valve: study of a case, together with suggestions of a new form of surgical therapy. Dis Chest 1958;33:297-304.

4. Barnard CN, Schrire V. Surgical correction of Ebstein's malformation with prosthetic tricuspid valve. Surgery 1963;54:302-8.

5. Hardy KL, May IA, Webster CA, Kimball KG. Ebstein's anomaly: a functional concept and successful definitive repair. J Thorac Cardiovascular Surg 1964;48:927-40.

6. Lillehei CW, Kalke BR, Carlson RG. Evolution of corrective surgery for Ebstein's anomaly. Circulation 1967;35,36(Suppl): I116-8.

7. Timmis HH, Hardy JD, Watson DG. The surgical management of Ebstein's anomaly: the combined use of tricuspid valve replacement, atrioventricular plication, and atrioplasty. J Thorac Cardiovasc Surg 1967;53:385-91.

8. Carpentier A, Chauvaud S, Mace L, Relland J, Mihaileanu S, Marino JP, et al. A new reconstructive operation for Ebstein's anomaly of the tricuspid valve. J Thorac Cardiovasc Surg 1988; 96:92-101.

9. Chauvaud SM, Mihaileanu SA, Gaer JAR, Carpentier AC. Surgical treatment of Ebstein's malformation-the "Hopital Broussais" experience. Cardiol Young 1996;6:4-11.

10. Augustin N, Schmidt-Habelmann P, Wottke M, Meisner H, Sebening F. Results after surgical repair of Ebstein's anomaly. Ann Thorac Surg 1997;63:1650-6.

11. Danielson GK, Driscoll DJ, Mair DD, Warnes CA, Olivier WC Jr. Operative treatment of Ebstein's anomaly. J Thorac Cardiovasc Surg 1992;104:1195-202.

12. Anderson RH, Becker AE. Cardiac anatomy: an integrated text and colour atlas. London-Edinburgh: Gower Medical PublishingChurchill Livingstone; 1980. p. 3.2-3.3.

13. Rusconi PG, Zuberbuhler JR, Anderson RH, Rigby ML. Morphologic-echocardiographic correlates of Ebstein's malformation. Eur Heart J 1991;12:784-90.

14. Leung MP, Baker EJ, Anderson RH, Zuberbuhler JR. Cineangiographic spectrum of Ebstein's malformation: its relevance to clinical presentation and outcome. J Am Coll Cardiol 1988; 11:154-61.

15. Shiina A, Seward JB, Tajik AJ, Hagler DJ, Danielson GK. Twodimensional echocardiographic-surgical correlation in Ebstein's anomaly: preoperative determination of patients requiring tricuspid valve plication vs replacement. Circulation 1983;68:53444.

16. Shiina A, Seward JB, Edwards WD, Hagler DJ, Tajik AJ. Twodimensional echocardiographic spectrum of Ebstein's anomaly: detailed anatomic assessment. J Am Coll Cardiol 1984;3:356-70. 